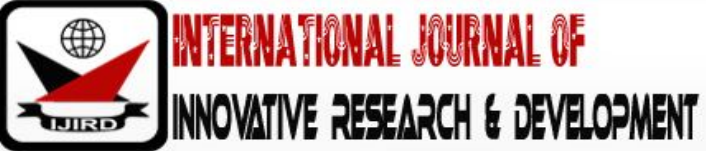

ISSN 2278 - 0211 (Online)

\section{Development of a Robotic Ceiling Painting System Using Applic-37 Development Kit}

\author{
Mohammed Kudu Omar \\ Relationship Manager, Department of Business Development, Wema Bank Plc, FCT, Nigeria
}

\begin{abstract}
:
This paper describes the development of a ceiling painting robotic system that is programmed to carry out painting tasks Specifically, the paper explains my design and construction of a robotic frame, steering, ladder, slider, brush and paint compartment, using a computer program (c language) in conjunction with APPLIC 37 development kit (a microcontroller) as a means on control. Direct Current (DC) motors are responsible for the various actions of the ceiling painting robot. These actions include a linear (vertical) movement of the robot, an upward movement of the ladder, back and forth movement of the slider, and spinning of the brush. Simplicity and relatively low weight were considered in my design. Different modules constituting the robot have been separately tested, then integrated. Experiments have shown the successfulness of the robot in its intended tasks. Human climbers painting ceilings and other industrial towers have sustained various degrees of injuries over the years, with few recorded death cases. According to the Occupational Safety and Health Administration, the most dangerous thing a worker can do is climb a ladder. However, there is a huge element of safety with robot painting, and my results show that using c language and APPLIC 37 development kit allows for more robotic painting precision.
\end{abstract}

Keywords: Robotics, software, microcontroller, efficiency

\section{Introduction}

In this paper, I describe how I design and construct a ceiling painting robotic system (CPRS) using DC motors and APPLIC-37 Development kit. The term robot implies different meanings to different people. Painting robots are ingenious machines that use intelligent control but vary in sophistication. Generally, they are designed to increase speed, efficiency and accuracy of painting operations [5]. Painting robots are especially helpful where the painting is done under dirty and dangerous conditions.

In construction engineering, the use of manual labour for various construction activities or task is becoming more and more popular, painting being the area of concern in this case. Different painting machines, robots, and techniques can be used for painting both internal and external walls and ceilings of a building. It is also very difficult and cumbersome for humans to work in an upright position, especially when painting ceilings for a long time. Painting in an upright position is also very dangerous to the eyes. To overcome this difficulty, a robotic system which can paint the ceiling of houses and buildings is proposed and developed. A CPRS will help ease the problems and inconveniences associated with upright painting (especially ceiling painting). This serves as the motivation for the project described in this paper.

The design and construction of the CPRS involves software design (programming and emulation of the microcontroller) and hardware implementation (development and construction of the microcontroller-based ceiling painting robotic system). Development of a CPRS entails the following: first, I systematically define my problem and develop an algorithm to carry out the various processes. Second, I design the hardware and lay out the construction process; these involve the design and development of the robotic frame and connections between the DC motors and the APPLIC 37 development kit. Finally, the software part involves the design and development of the system control software. This includes a logical sequence of instructions, understood by the microcontroller to carry out the detail specified by the problem. C Language is chosen because of its flexibility and nearness to precision. Overall, the methodology I adopt in the development of the robotic system involves the design of the robot wheels, design of the ladder, slider, brush and paint compartment, programming of the robotic machine, and construction and testing of the robotic machine.

This paper is organized as follows. In Section 2, I presenta review of literature. In section 3, I discuss the theoretical background. Next, I present the design process in Section 4. In Section 5, I discuss my results, and I conclude the paper in Section 6.

\section{Literature Review}

For robots to interact with their environment, they must be able to convert electrical signals into motion. Besides, the power requirement of activators (motors), and electrical devices which are capable of producing motion are typically so high that normal digital circuitry cannot drive them. 
The University of Texas developed a prototype automated surface finishing system for use on large diameter tanks. This system uses a computer controller motion module to refinish the vertical exterior walls of the tank. The module is configurable for both blasting and painting, and utilizes the conventional surface finishing equipment for these processes. This system consists of an aluminum motion module which rolls on the surface. My design is a prototype model which rolls on the surface of the ceiling. The nodule attaches to the wind girt of a tank via two steel cables [9]. In2001, Ohene [6] designed a P1C16F628 microcontroller-based obstacle avoiding vehicle. In 2008, Egbe [3] designed a robotic lint automated machine using Fishertechnik opponents and SESLOGO software. My design builds on these by using their software idea. However, unlike the prior designs, I use an APPLIC 37 controller and C language because of they increase the precision of the CPRS.

Robotics are being applied to improve efficiency of painting in narrow space [2], self-adjusting painting [7], agriculture [8], tiling of contemporary glass mosaics [4], and in building construction [1]. In many aspects of life, robots overcome man-made faults, increase speed, and allow for flexibility [5]. Thus, the need for more research into robotics.

\section{Theoretical Background}

\subsection{Robot Definition}

A robot is any automatically operated machine that replaces human efforts, though it may not resemble human beings in appearance or perform functions in a humanlike manner [5]. A CPRS is a robotic machine that uses its preprogrammed instructions in the execution of the painting task especially for ceilings or surfaces that are upright. The robot has the following properties: it moves without human intervention, programmable, artificially created, senses its environment and interacts with things in it, and has the ability to make choices based on the environment, often using automated control or a preprogrammed sequence $[2,7]$.

\subsection{Theory of DC Motors}

An electrical motor is a machine capable of converting electrical energy into mechanical energy. The basic principle of such conversion rests upon the experimental fact that when a current flow in a region occupied by a magnetic field, a reaction is set up which tends to move the current out of the field. When this force is utilized to do mechanical work, the electrical energy of the current is changed to mechanical energy of motion, and the arrangement constitutes and electric motor.

\subsection{Operating Principle of Dc Motors}

All electrical machines have two members known as stator (stationary part) and rotor (rotary part). In DC machines, the stator has what is known as salient poles or projected poles. The action of flux motor is based on the principle that when a current carrying conductor is placed in a magnetic field, it experiences a mechanical force whose direction is given by Fleming's left-hand rule, and magnitude is given by:

- $\quad \mathrm{F}=\mathrm{BIL}$ (Newton)

- $\mathrm{F}=$ Force of attraction

- $\mathrm{B}=$ Magnitude flux

- $\mathrm{I}=$ Current in conductor

- $\mathrm{L}=$ Length of conductor

Therefore, motoring operation is achieved in a DC motor when a voltage source is applied to the stator (field winding) of the motor. Because of this applied voltage, current will start to flow in the field of the stator. This current sets up a magnetic flux which will lead to an interaction between the field windings and the conductor of the armature hence a force is produced which tends to rotate the armature is known as the interaction principle given in equation (2.1). Figure 1 shows a two pole DC motor in which its field windings are supplied with a DC voltage.

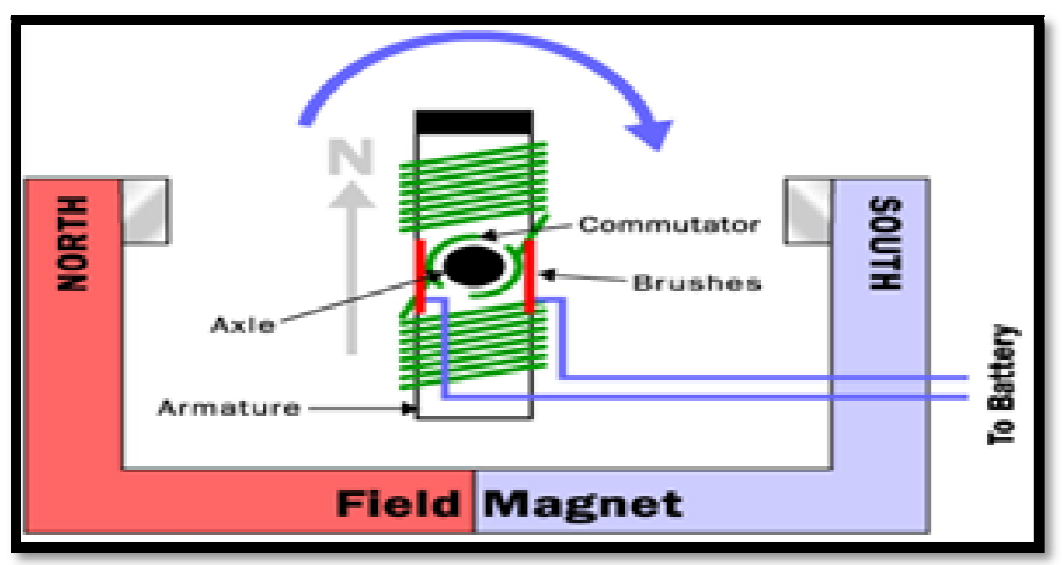

Figure 1: A two pole DC motor ${ }^{1}$ 
Now, as soon as the armature starts rotating dynamically or motional, induced emf is produced in the armature conductors. The direction of this induced emf is known as back emfEb or counter emf. The values of this emf is given as

$$
E_{b}=\frac{P Z}{2 \pi a} \emptyset w
$$

- $\quad \mathrm{P}=$ Number of paired poles

- $Z=$ Number of armature conductor

- $\mathrm{a}=$ Pair of parallel paths

- $\mathrm{w}=$ Angular speed of the rotor in reaction per speed

- $\phi=$ Field flux

The circuit model of a DC motor is shown in Figure 2. From the circuit, the armature current is opposing the back emf.

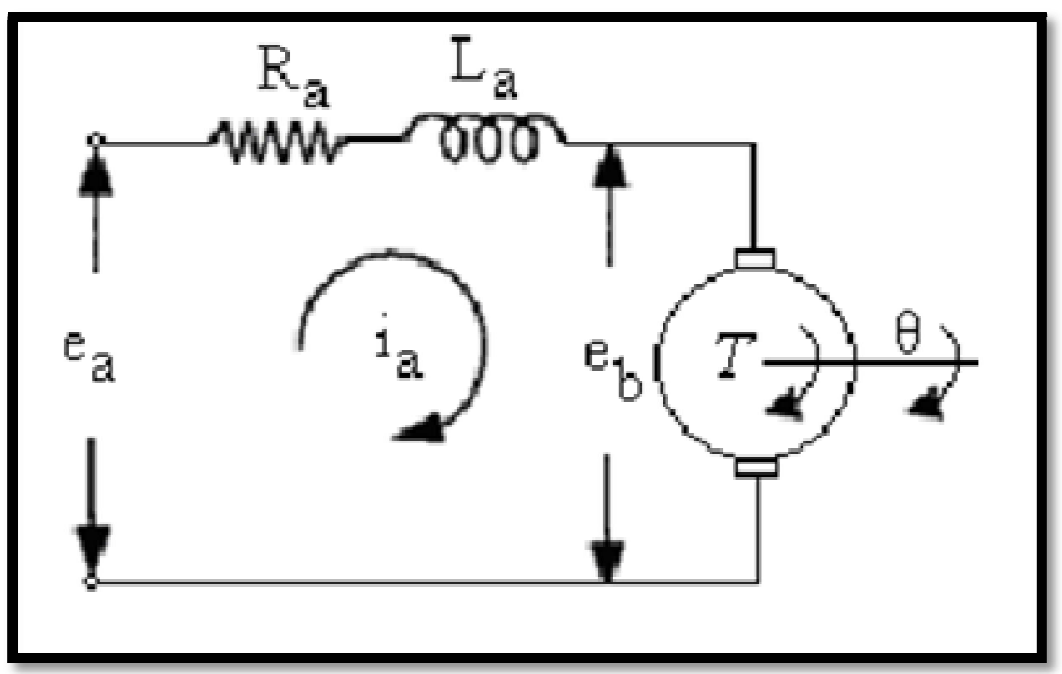

Figure 2: Circuit Model of A DC Motor²

\subsection{The Control System}

\subsubsection{Preface}

The term "control systems" comprises two separate terms, which can be defined individually: A system is a combination of a number of components, which are interconnected and operate as a unit, in order to achieve a specific goal. Control is the ability to maintain command over a set of variables. A "control system" may be defined as a group of components, which can be operated together to control various variables, which govern the behaviour of the system. The human body has systems, which control body temperature.

A Speed control system is always steady regardless of the changing loads on the motor. A light control system can maintain a steady level of light, regardless of the amount of available sunlight. Lamps will be switched ON or OFF, when there is not enough natural light, according to the required light level. When there is need to combine the control system with a convenient method of changing its operation condition a "computerized control system" may be chosen.

A computerized control system allows the use of a computer and computer software to supervise the operation of a control system. These operations can easily and cheaply be changed by making software modifications, without making any complicated modifications of the control system. It is not necessary to make any changes in the electric circuitry. It is not necessary to design new electronic circuits. All that is required is to adapt the computer program to the new operating conditions and to run the system. The controller as in Figure 3 has all the units of a typical computer, but must also be equipped with units, which enable it to be connected to external electrical devices. 


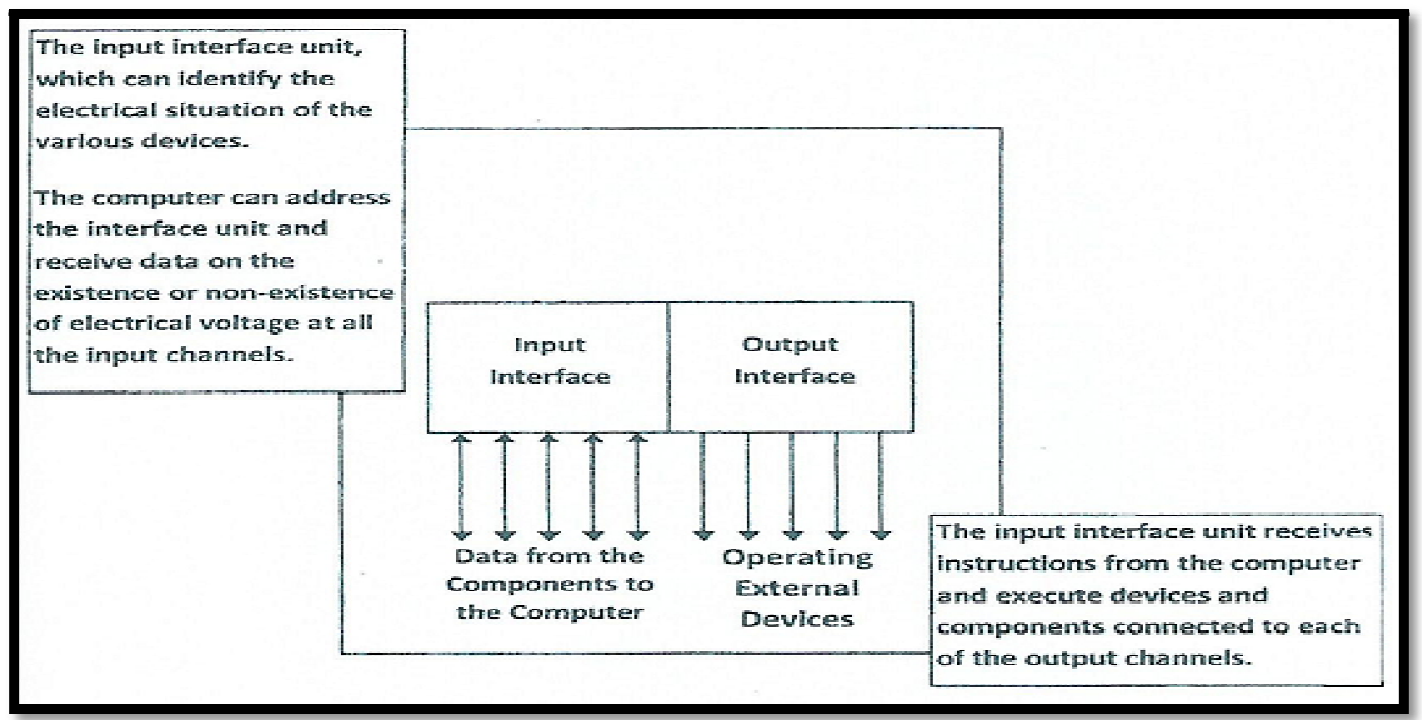

Figure 3: Controller

There is the need to connect various components and devices to a control computer. Input devices such as switches or measuring devices, while output devices such as motors, lights, solenoids etc. can be operated by the computer. Input and output devices cannot be connected directly into the computer's CPU. Some kinds of intermediary devices are needed. An electronic circuit, which arbitrates between the CPU and the various input and output devices is called an INTERFACE as in Figure 4. The interface may be seen as an electronic box, which is connected to various devices at one end, and to the computer at the other end.

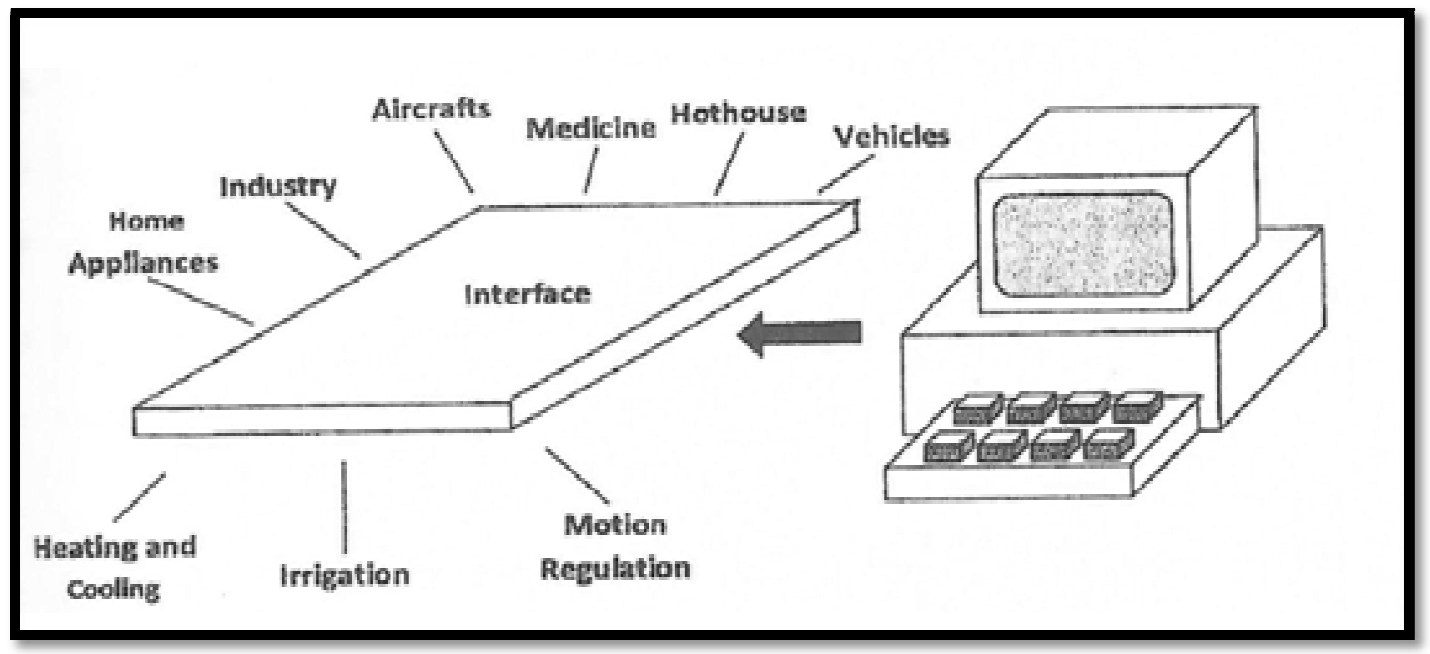

Figure 4: Interface

Some units may also be bi-directional, i.e. input/ output. They may feed data into the computer or extract data from the computer. In this project, APPLIC-37 module of SES is used as an input/ output interface. The APPLIC-37 interface is used to connect the control devices we practice with to the computer. It has 8 digital input channels, 8 digital output channels, 8 analog inputs, and 2 analog outputs. There are many ways of programming a Controller: LOGO1, BASIC, High level or assembly programming, $\mathrm{CH}$, visual basic, $\mathrm{C}$ and others. There are also special programming methods for controlling - flow charts, ladder diagrams or control diagrams. In this project, programming methods involves the use of $\mathrm{C}$ language.

\subsection{Installing the Interface}

The APPLIC37 interface as in Figure 5 is a controller, which receives commands or a program from the computer. The interface performs the commands immediately and stores the program in its non-volatile memory (data in the memory is saved even after the power is OFF). The command "RUN" runs the program. When the interface receives a new program, the new program replaces the previous one stored in the memory. 

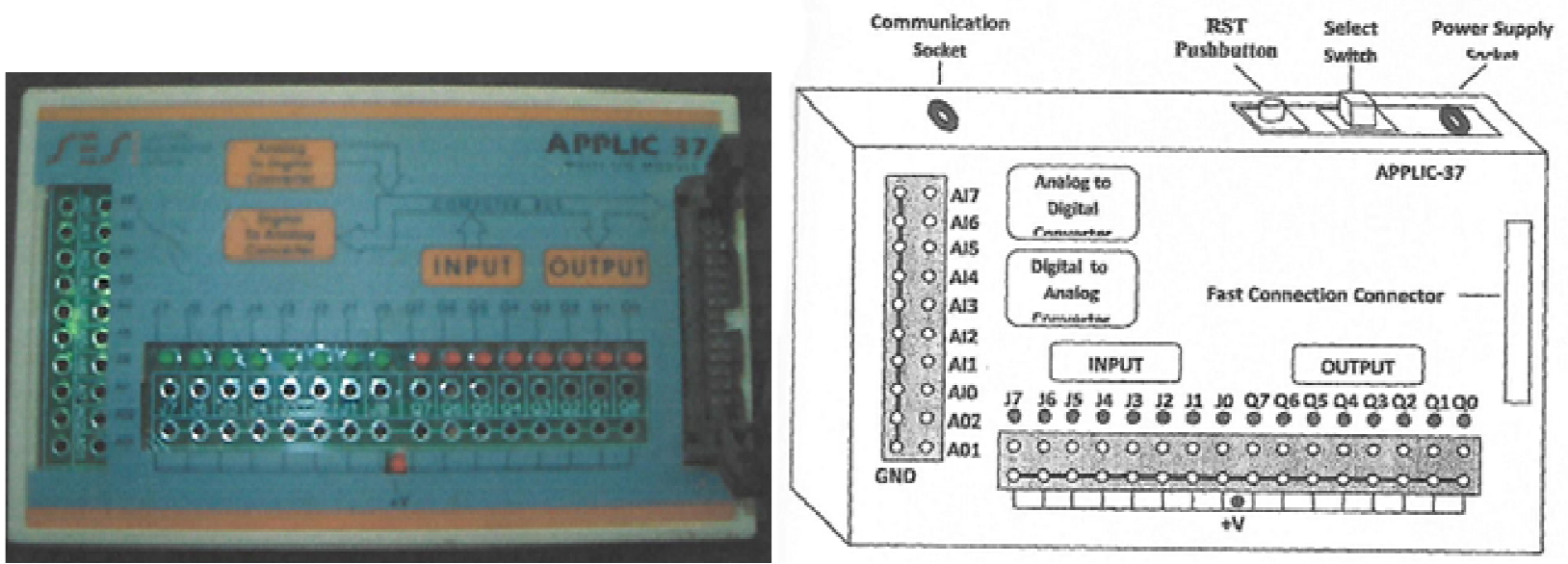

Figure 5: APPLIC-37 interface

The interface includes eight digital output channels (Q7-Q0), eight digital input channels (J7-J0), two analog output channels (A02, A0l) and eight analog input channels (A17- Al0). A digital output channel helps in operating a motor or lamp in two levels - ON and OFF. An analog output channel helps to output different voltages to a motor or to a lamp in a continuous manner at $0-10 \mathrm{~V}$ range.

A digital input channel identifies a sensor or a switch in two levels only-ON and OFF (0 and 1). An analog input channel enables users to read a sensor value (voltage) at $0-5 \mathrm{~V}$ range. This interface includes banana plugs inlets for input and output channels. A line of banana plugs inlets is located against the digital output channels (Q7-Q0) and the digital input channels (J7-JO). All these points are connected to the $+\mathrm{I} 2 \mathrm{~V}$ voltage line. Another line of banana plugs inlet is located against the analog output channels (A02, A0l) and the analog input channels (A17-Al0). All these points are connected to the OV (GND) line. The GND line is the negative pole of the voltage source [10]. The interface also includes flat cable connector. This connector enables a permanent connection of the interface to a controlled system. Connecting and disconnecting the interface to the controlled system can be done very fast with the flat cable connector [10]. A number of components are installed on the rear side of the interface. Figure 5 shows the APPLIC 37 interface. The communication cable to the computer has earphone plug at one side and a D connector (D) with nine pins on the other side. Insert the earphone plug into the communication socket on back of APPLIC-37. Locate the communication sockets on the back of the computer (D connectors with nine pines). Usually, there are two communication channels called COMI and COM2. Connect the cable connector to the communication socket in the computer.

\section{Design Process}

\subsection{Linear Movement}

The overall movement (vertical) of the robot is controlled by three wheels; One front wheel and two rear wheels. One of the wheels (the front wheel) is attached to a DC motor. These wheels serve as legs for the robot. The movement of the rear wheels depends on the action of the front wheel.

\subsection{The Brush}

The brush is designed to rotate in a clockwise direction, and it is embedded in a compartment which carries the paint. A reasonable portion of the brush is exposed to give space for effective painting. The brush is designed to rotate continuously throughout the entire painting period and this period will depend on the choice or specification of the designer. The brush is attached to a motor that rotates it.

\subsection{The Ladder}

The ladder carries the slider, brush, and the brush compartment. The ladder is designed to push the slider (carrying the brush) upwards for one second. The ladder is also designed to roll down after the entire painting exercise. It is controlled by a DC motor.

\subsection{The Slider}

The slider is the portion of the robot which is designed to move back and forth continuously with the brush and paint compartment directly on top of it. The purpose of this back and forth movement is to ensure that a reasonable portion of the ceiling is painted per cycle. The direction of this movement will depend on the program controlling it. 


\subsection{The Steering}

The steering is designed to change the direction of motion of the robot when an obstacle is encountered. This steering is controlled by One DC motor and its operation is such that it turns the front wheel either clockwise or anticlockwise (depending on program).

\subsection{Program Description}

A program can be defined as a collection of instructions for the execution of a specific task by a computer for the purpose of this project; C-language is employed as the programming language and is it's then subsequently downloaded into the [11]. APPLIC37 micro controller. The C-language enables the operation of the APPLIC- 37 interface directly, clicking over a command button causes the interface to execute it. Building devices that include motors can be addressed directly

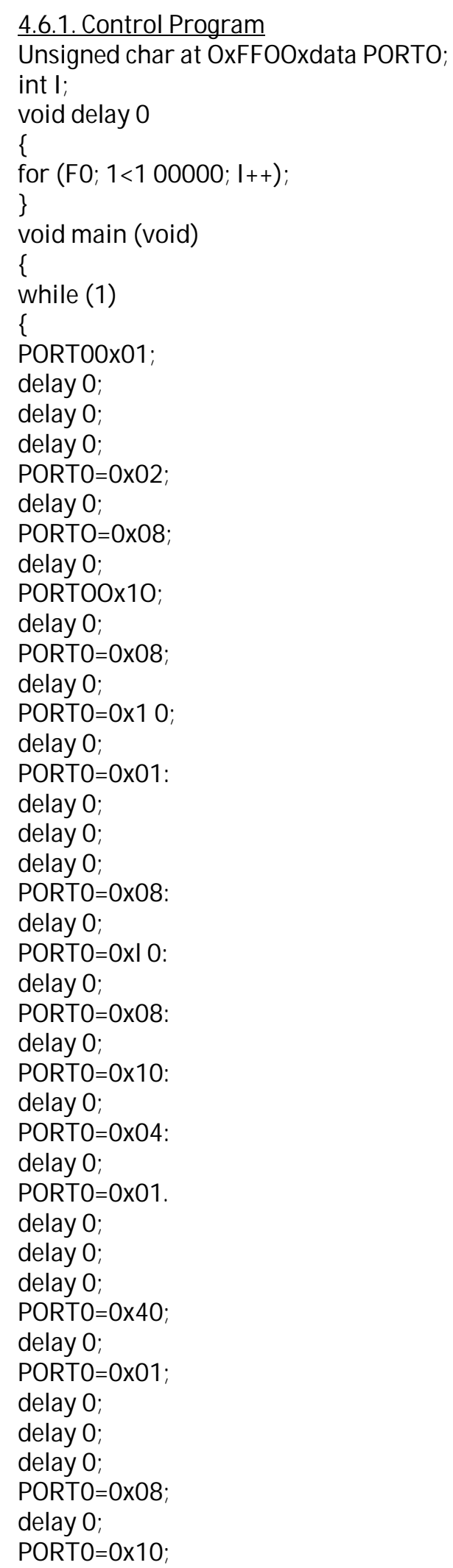




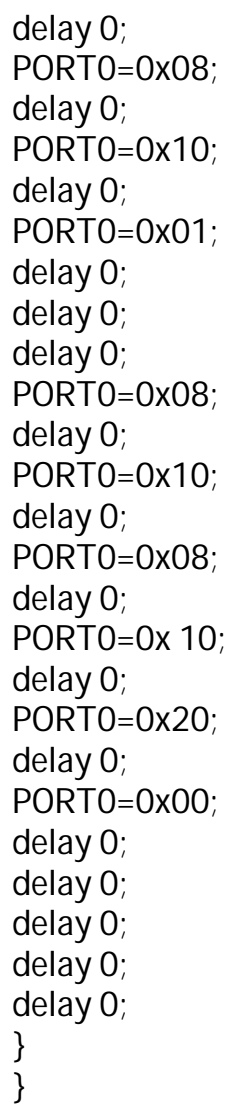

\section{Results and Testing}

In Section four, I presented the development of the software and hardware. In this section, I describe integrating the software and hardware to form a complete composite high-end application system.

\subsection{Integration}

The task of bringing the model to life is achieved completely by integrating the hardware and software to meet the desired goal. This is achieved by connecting the various motor terminals to the I/ O ports of the APPLIC 37 development kit. A first attempt of this robotic model did not perform according to specification. A second attempt was made and this produced better results. Pictorial representations of the final and first attempts are shown on Appendix 3 and Appendix 4.

\subsection{Testing}

The various terminals of the motors are connected to the I/ O ports of the APPLIC 37 Development kit. The Robot makes an initial linear movement for two seconds then halts. The ladder pushes the slider; carrying the brush and paints compartment upwards for one second. This operation is followed by the back and forth movement of the slider while the brush is rolling and picking up paint from the paint compartment. This brush action results in the painting of the ceiling. When an obstacle is encountered, the front wheel is steered causing the robot to change direction. This sequence continues until the robot is turned off.

\subsubsection{Testing of the Ladder}

The ladder is that portion of the robot that pushes up the slider, brush and paint compartment for one second. Pictorial representations of the initial position of the ladder and the position of the ladder after the time interval are shown in Figure 6 and Figure 7.

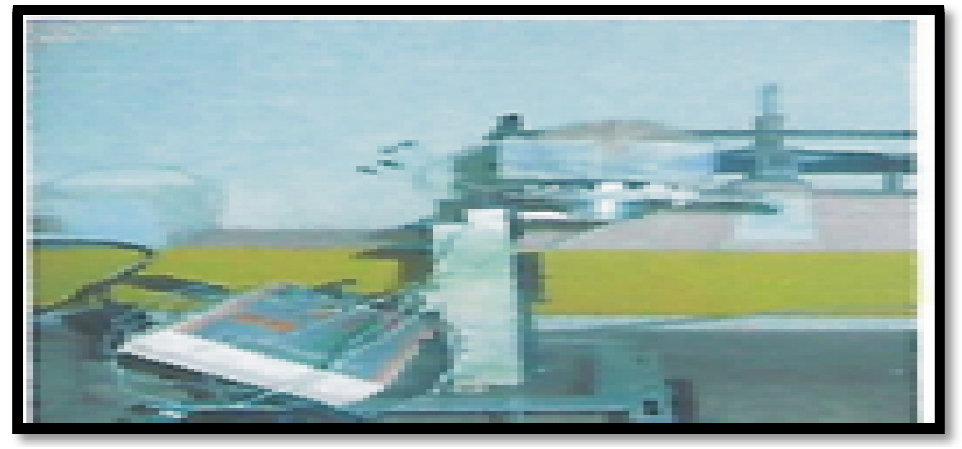

Figure 6: Ladder Picture at Rest 


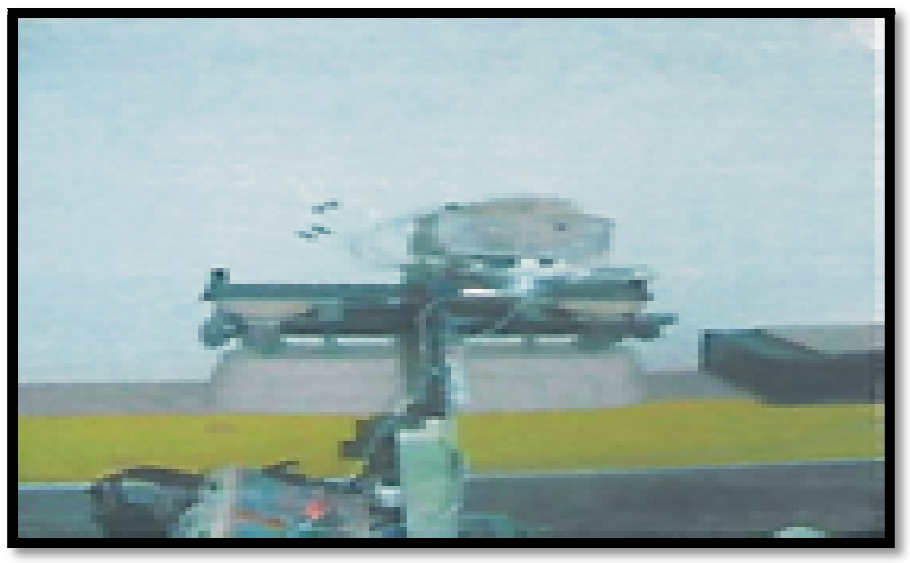

Figure 7: Ladder Picture after Moving Upward

\subsubsection{Testing of the slider}

The slider carries the brush, paint and the paint compartment. It is designed to move back and forth continuously for the duration of the time the painting will take place. Pictures of the initial and final positions of the slider are shown in Figure 8, Figure 9, and Figure 10.

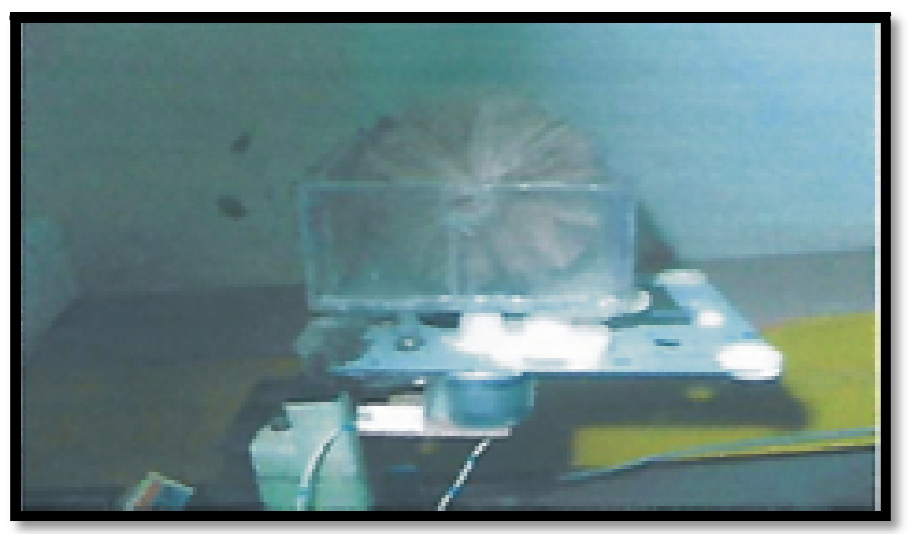

Figure 8: Initial Position of the Slider

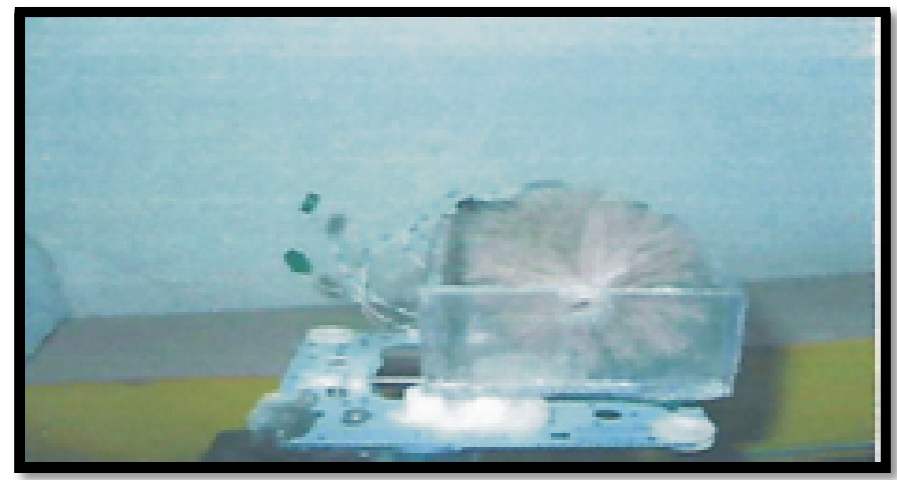

Figure 9: The slider after moving forward

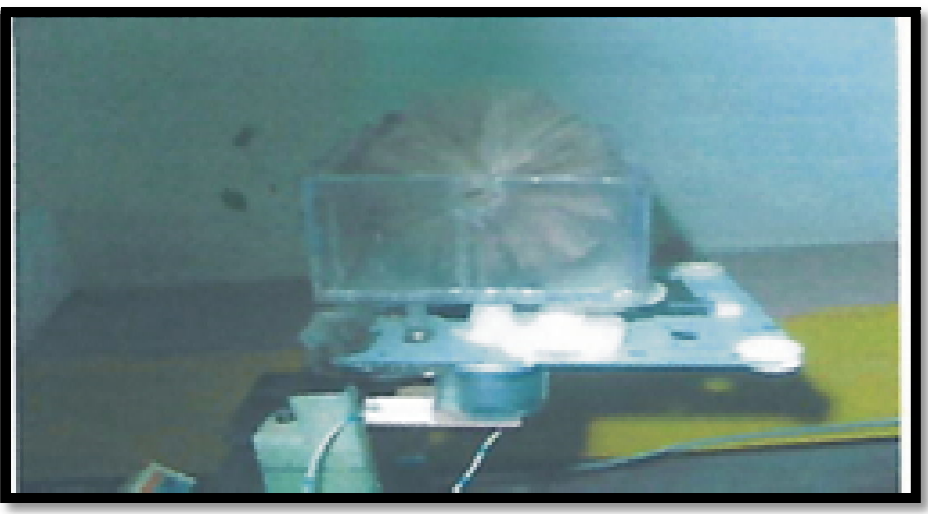

Figure 10: The Slider, after Returning to Its Initial Position 


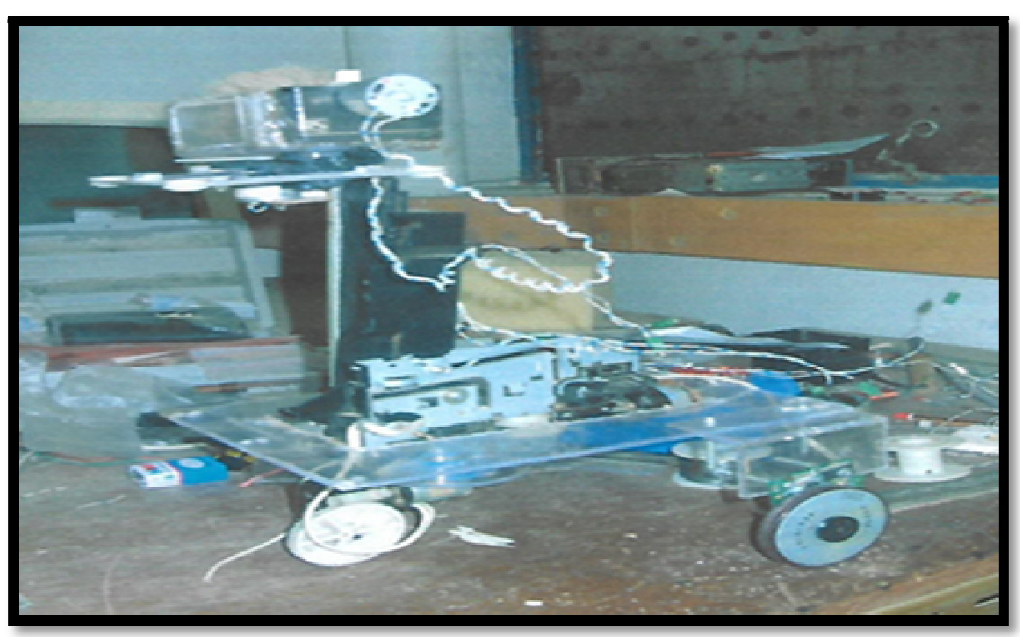

Figure 11: The Ceiling Painting Robot

\section{Conclusion and Recommendation}

In this paper, I describe the design and construction of a ceiling painting robot. I demonstrate how a computer program can be used to carry out some specific task without human intervention. Although this project is just a model, it offers the attraction of a standard development platform and available high-end application software including a standard programming language. Furthermore, it can reduce the use of manual labour and ease the work done by human beings. Various physical components including motors were incorporated to build up the model. The result obtained shows that robots can be used in places where human beings may find it unsuitable to work.

Limitations of my design is that the robot designed and constructed is a prototype model and this caused constraints on the design and construction process. This can affect the overall performance of the robot resulting in slow response time, sluggishness, and mechanical and electrical faults of the robot. Also, the APPLIC 37 Development kit can handle a maximum of four components. This limited the number of components used in my design.

Future research opportunities exist. First, a PIC microcontroller will be more suitable as a means of control for the robot since it has the capability of controlling more components. Second, a logic circuit which consists of a combination of multivibrators can be used as a means of control because pulses can easily be generated based on timing circuitry to control each functional part of the robot. This is in a bid to aid the overall stability since geared motors do not move or rotate unless they are powered.

\section{Acknowledgements}

The robotic design project was my thesis at Ahmadu Bello University Zaria. My gratitude goes to my project Supervisor, Dr. M.B.Mu'azu whose patience, understanding, and uncompromising attitude for excellence made the outcome successful. I appreciate the efforts of all the lecturers of the Department of Electrical Engineering, Ahmadu Bello University Zaria, for the knowledge they impacted on me over the years. I also appreciate the efforts of the Robotics Lab Technologist, MallamTukur Lawal, for his lengthy involvement and assistance in the completion of my design.

\section{References}

i. Bock, T., Parschin, D. \&Bulgakov, A. (2002). "Robotization of mounting and finishing operations in building." Robotica, 20 (2), 203-207.

ii. Chen, Y., Chen, W. Z., Chen, K., Shao, J. Y., \& and Zhang, W. M. (2014). "Development of Robotic Spraying System in Narrow Space." In Applied Mechanics and Materials, 442, 221-224. Trans Tech Publications.

iii. Egbe, A. O. (2008), Design and construction of a Robotic lint automated machine using SESLOGO, Unpublished final year project, Department of Electrical Engineering, Ahmadu Bello University, Zaria.

iv. Kaya, B., Berkay, A., \&Fehmi, E. (2005). "Robot assisted tiling of glass mosaics with image processing.”Industrial Robot: An International Journal, 32 (5), 388.

v. Nurmaini, S. (2013). "Robotics Current Issues and Trends." Computer Engineering and Applications Journal, 2 (1), $117-120$

vi. Ohene, P. U. (2001). Design, construction, and testing of a light seeking Robot prototype, Unpublished final year project, Department of Electrical Engineering, Ahmadu Bello University, Zaria. Omar, M., Viti, V., Saito, K., \& Liu, J. (2006). "Self-adjusting robotic painting system." Industrial Robot: An International Journal, 33 (1), 50-55.

vii. Von Borstel, F. D., Jaime Suárez, E. R., \& Gutiérrez, J. (2013). "Feeding and water monitoring robot in aquaculture greenhouse." Industrial Robot: An International Journal, 40 (1), 10-19.

viii. www.arc.Zone.com/index.php.

ix. www.sistenexus.com/glossary/r.html

x. www.tki.org.nz/r/technology/ curriculum/ p85-86-e-php. 